\title{
Effects of standardized extracts of Lamium album and Urtica dioica on rat tracheal smooth muscle contraction
}

\author{
Samane Arefani', Seyyed Mohammad Mohseni Mehran², Hassan Moladoust ${ }^{3}$, \\ Mohammad Reza Norasfard ${ }^{1}$, Ahmad Ghorbani ${ }^{4}$, Mahmood Abedinzade ${ }^{5}$
}

\footnotetext{
1 MSC, Department of Physiology, Faculty of Medicine, Guilan University of Medical Sciences, Rasht, Iran

2 Department of Physiology, Faculty of Medicine, Guilan University of Medical Sciences, Rasht, Iran

${ }^{3}$ Associate Professor, Department of Biophysics and Biochemistry, Faculty of Medicine, Guilan University of Medical Sciences, Rasht, Iran

${ }^{4}$ Associate Professor, Pharmacological Research Center of Medicinal Plants, Mashhad University of Medical Sciences, Mashhad, Iran

${ }^{5}$ Associate Professor, Medical Biotechnology Research Center, Faculty of Paramedicine, Guilan University of Medical Sciences, Rasht, Iran
}

\section{Key Words}

Asthma; herbal medicine; lung .

\begin{abstract}
Objective: Diseases of the respiratory system are one of the main causes of death and include situation such as chronic obstructive pulmonary disease, pneumonia or asthma. Medicinal plants have beneficial effects on multiple diseases include respiratory disorders like asthma and bronchitis. The aim of this study was to evaluate the effects of U. dioica and L. Album on tracheal smooth muscle contraction.
\end{abstract}

Material and methods: Hydroalcoholic extracts of L. Album and U. Dioica aerial parts were prepared by maceration method and standardized based on their total phenol content. The effect of the extracts on the KCl-induced contraction of rat trachea was examined in an organ bath chamber. Data was analyzed with spss software 22 .

Results: The extract of L. Album (5 mg/ml), similar to theophylline (20 mM), significantly reduced the KCl-in-

Received: May 10, 2017 Reviewed: Mar 16, 2018 Accepted: Mar 30, 2018

(c) This is an Open-Access article distributed under the terms of the Creative Common Attribution Non-Commercial License (http://creativecommons.org/licenses/by-nc/4.0/) which permits unrestricted noncommercial use, distribution, and reproduction in any medium, provided the original work is properly cited.

(2) This paper meets the requirements of KS X ISO 9706, ISO 9706-1994 and ANSI/NISO Z39.48-1992 (Permanence of Paper). duced tracheal contraction. On the other hand, U. Dioica $(1 \mathrm{mg} / \mathrm{ml}$ and $5 \mathrm{mg} / \mathrm{ml}$ ) augmented the KCl-induced contraction.

Conclusion: The relaxant effect of L. Album on the trachea makes it as a candidate for the managing patients with asthma and obstructive pulmonary diseases. But because of U. Dioica potential constrictive effect on the trachea it is suggested that patients avoid consuming it.

\section{Introduction}

Ischemic heart disease, stroke, chronic obstructive lung disease and lower respiratory infections have remained the top killers during the past decade. Chronic diseases cause increasing numbers of deaths worldwide. According to WHO estimates, 235 million people suffer from asthma. Asthma is the most common chronic disease among children. Asthma is not just a public health problem for high income countries: it occurs in all countries. Over $80 \%$ of asthma deaths happen in low and lower-middle income countries. Asthma is under-diagnosed and under-treated, creating a substantial load to individuals and families and possibly restricting individuals' activities for a lifetime 1 . 
Airway smooth muscle is responsible for the acute constriction of the trachea and bronchi in asthma and chronic obstructive pulmonary disease (COPD). Therefore, it is the main target in the pharmacotherapy of these diseases. Agonists of 2 -adrenoceptors and muscarinic antagonists are currently available drugs for rescue from airflow obstruction in asthma and COPD.2, 3 Considering developing tolerance to these drugs and their potential adverse effects, the search for new bronchodilator agents is of great interest. 4,5 In this context, the relaxant effect on airway smooth muscle has been reported for several medicinal plants and some natural polyphenols. 6-8

L. Album L. (White dead nettle) is a polyphenol-rich medicinal plant in the family of Lamiaceae.9 Experimental studies showed that the Album has antioxidant, antimicrobial, hypoglycemic, cytoprotective, and anticancer activities.10-13 Also, beneficial effects of L. Album have been reported on respiratory disorders including asthma and bronchitis. 14

U. Dioica, also known as stinging nettle, belonging to the family of Urticaceae. It has been shown that U. Dioica has hypoglycemic, antioxidant, antimicrobial, analgesic, and anticancer effects.15-17 Recently, Qayyum et al. Observed that U. Dioica extract induces a relaxant effect on the rabbit thoracic aorta. However, until now, there is no report on the effects of U. Dioica on airway muscle contraction. ${ }^{18}$

Since there was no available data about the effects of L. Album and U. Dioica extracts on the trachea, the aim of this work was to test the potential relaxant effect of these extracts on the trachea in organ bath condition.

\section{Materials and Methods}

\subsection{Preparation of L. Album and U. Dioica extract}

The plants L. Album and U. dioica (Fig. 1) were collected from Rasht region in Guilan Province, Iran. They were identified by Fatemeh Yousefbeyk, Department of Pharmacognosy, Guilan University of Medical Sciences, Iran (voucher specimen No. 202HGUM and 156HGUM for L. Album and U. Dioica, respectively). For each plant, the hydroalcoholic extract was prepared by macerating the powder of stems and leaves in $50 \%$ ethanol $(10 \mathrm{ml} / \mathrm{g}$ powder $)$ for $72 \mathrm{~h}$ at $40{ }^{\circ} \mathrm{C} .19$ Then, the extracts were filtered through mesh $250 \mu \mathrm{m}$, centrifuged $10 \mathrm{~min}$ at $2000 \mathrm{RPM}$, and their supernatants were dried on a water bath $\left(40^{\circ} \mathrm{C}\right)$.

\subsection{Standardizing L. Album and U. Dioica extract}

The extracts were standardized based on their total phenol content by the Folin-Ciocalteu method. A sample of each extract $(20 \mu \mathrm{L}$ of $10 \mathrm{mg} / \mathrm{ml})$ was mixed with the Folin-Ciocalteu reagent $(100 \mu \mathrm{L})$ and sodium carbonate solution $(300 \mu \mathrm{L}, 1 \mathrm{M})$, and the volume was adjusted to 2 $\mathrm{ml}$ with deionized water.20 After $2 \mathrm{~h}$, the absorbance was measured by the spectrometer at $765 \mathrm{~nm}$. The standard curve was prepared for Gallic acid and the total phenol content of the extracts was expressed as milligram of Gallic acid equivalents.

\subsection{Animals}

Male albino Wistar rats (200-250 g) were used in this study. They were kept in a standard room with controlled lighting ( $12 \mathrm{~h}$ light and $12 \mathrm{~h}$ darkness) at a temperature of $22 \pm 2^{\circ} \mathrm{C}$. The animals were having free access to food and tap water ad libitum. The protocol of this study complied with the guidelines of the animal care of Guilan University of Medical Sciences.

\subsection{Smooth muscle preparation and incubations}

The animals were anesthetized with an intraperitoneal injection of thiopental $(50 \mathrm{mg} / \mathrm{kg})$. The chest was opened and a piece of the trachea (length $1 \mathrm{~cm}$ ) was removed and placed in cool and oxygenated Krebs solution $\left(37^{\circ} \mathrm{C}, \mathrm{pH}=\right.$ 7.4). Connective tissues were carefully removed and the trachea was split into two pieces. Each piece of the trachea ( $5 \mathrm{~mm}$ ) was mounted between the two hooks, one fixed at the bottom of the organ bath and the other connected to an isometric transducer. The organ bath contained Krebs-Henseleit solution ( $\mathrm{NaCl} 120 \mathrm{mM}, \mathrm{KCl} 4.72 \mathrm{mM}$, $\mathrm{CaCl} 22.5 \mathrm{mM}, \mathrm{MgSO} 40.5 \mathrm{mM}$, NaHCO3 $25 \mathrm{mM}, \mathrm{KH}-$ $2 \mathrm{Po} 41.2 \mathrm{mM}$, glucose $11 \mathrm{mM}$, pH 7.4). An initial tension of $1.5 \mathrm{~g}$ was kept for all stages of the experiments and an acclimatization period of $60 \mathrm{~min}$ was used. Contraction of the trachea was induced by $\mathrm{KCl}(60 \mathrm{mM})$. When the contraction reached a plateau, $0.1 \mathrm{ml}$ of $\mathrm{L}$. Album extract $(0.1$, 1 and $5 \mathrm{mg} / \mathrm{ml})$, U. Dioica extract $(0.1,1$ and $5 \mathrm{mg} / \mathrm{ml})$, theophylline $20 \mathrm{mM}$ (Sigma, T1633), or saline was added to organ bath and the changes in contractile force were recorded.21 Each incubation was repeated six times.

\subsection{Statistical analysis}

Data were analyzed with Spss software 22 with One-way analysis of variance and Turkey's tests. The results are presented as mean \pm SEM and $\mathrm{p}<0.05$ was considered statistically significant.

\section{Results}

\subsection{Phenolic content of the extracts}

Physio-chemical properties of L. Album and U. Dioica extracts are shown in Table 1. The solid residue of macerated hydroalcoholic extracts of L. Album and U. Dioica was $16.5 \%$ and $12.5 \%$, respectively. Total phenolic compound concentration was $70 \mathrm{mg}$ and $60 \mathrm{mg}$ Gallic acid equivalent per gram of the crude extract for L. Album and U. Dioica, respectively.

\subsection{Effect of L. Album on tracheal smooth muscle contraction}

The tracheal smooth muscle contraction induced by $\mathrm{KCl}$ was set at $100 \%$. As expected, theophylline as positive control significantly inhibited $(26 \pm 2.5 \%, \mathrm{p}<0.001)$ the KCl- induced contraction (Fig. 1). Similarly, the extract of L. Album at a concentration of $5 \mathrm{mg} / \mathrm{ml}$ exhibited a significant relaxant effect $(16 \pm 3.1 \%, \mathrm{p}<0.05)$ on the trachea 
(Fig. 2).

\subsection{Effect of U.Dioica on tracheal smooth muscle contraction}

Figure 4 shows the effect of U. Dioica extract on tracheal smooth muscle contraction. This extract at concentrations of $1 \mathrm{mg} / \mathrm{ml}$ and $5 \mathrm{mg} / \mathrm{ml}$ augmented the KCl-induced contraction of $11 \pm 1 \%(\mathrm{p}<0.05)$ and $18 \pm 1.6 \%(\mathrm{p}<0.05)$, respectively.

\section{Discussion}

In the present work, the effects of L. Album and U. Dioica extracts on the contraction of the trachea were evaluated in organ bath condition. First, we standardized the hydroalcoholic extracts of these plants based on their total phenol content and found that they are polyphenol-rich medicinal plants. With regard to our findings, previous studies revealed the presence of various phenolic compounds such as chlorogenic acid, caffeic acid derivatives, rutin, and quercetin 3-O-glucoside in L. Album and U. Dioica.9, 10,22

The results of the present work for the first time showed that the extract of L. Album, similar to theophylline, reduced the $\mathrm{KCl}$-induced tracheal contraction. The relaxing effects of phenolic compounds such as rutin, quercetin, and caffeic acid derivatives on human isolated bronchus have been previously reported.6,23 .Therefore, the relaxant effect of L. Album extract on trachea might be induced by its phenolic compounds.

The exact mechanisms by which L. Album relaxes trachea need to be determined by further studies. Previous studies revealed that the relaxant property of medicinal plants on tracheal smooth muscle could be achieved by calcium channel-blocking effect, potassium channel- opening activity, inhibitory effect on muscarinic receptors, histamine (the $\mathrm{H} 1$ receptor) antagonistic activity, stimulatory effect on $\bigotimes 2$-adrenoceptors, and methylxanthine activity.7 But the present study showed that U. Dioica extract augmented the $\mathrm{KCl}$-induced contraction of the trachea. In the literature, there are some conflicts about the effect of U. Dioica on the smooth muscle contraction. Dizaye et al. Reported that aqueous extract of the U. Dioica had no significant effects on the smooth muscle of the bladder and pulmonary artery in the rabbit.24 Qayum et al. Showed that methanolic extract of the U. Dioica has a relaxant effect on phenylephrine-induced contraction in rat aorta.18 where as Collier and Chesher revealed that U. Dioica string contains acetylcholine, histamine, and 5-hydroxytryptamine, and evokes contraction in the uterus of rats.25 These controversies may be due to the differences in the method of extraction, parts of the plant used for extraction, animal species, and source of tissues for smooth muscle isolation. In conclusion, the results of the present study suggest that the album has a relaxant effect on the tracheal smooth muscle and might be a candidate for the management of patients with asthma and obstructive pulmonary diseases. Also, it is suggested that these patients, avoid consumption of the U. Dioica because of its potential constrictive effect on the trachea.

\section{Acknowledgments}

This work was financially supported by the Guilan University of Medical Sciences, Rasht, Iran and extracted from MSC student thesis. The authors declare that they have no competing interests.

Funding : Research deputy of Guilan University of Medical Sciences.

All authors read the manuscript and declare that there is no conflict of interest. 
Table 1. Physio-chemical properties of macerated extracts of L. Album and U. dioica.

\begin{tabular}{lllll}
\hline \multicolumn{2}{l}{ Plant materials } & Extract & Solid residue & Phenolic content \\
\hline \hline L. Album (stems & and & Hydroalcoholic (50\%) & $16.5 \%$ & 70 (mg/g extract) \\
leaves) & & & & \\
\hline U. dioica (stems and leaves) & Hydroalcoholic (50\%) & $12.5 \%$ & $60(\mathrm{mg} / \mathrm{g}$ extract)
\end{tabular}

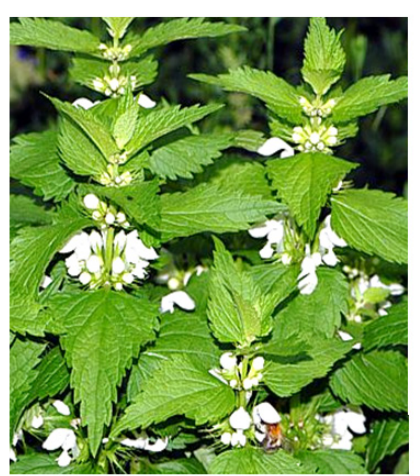

Lamium album

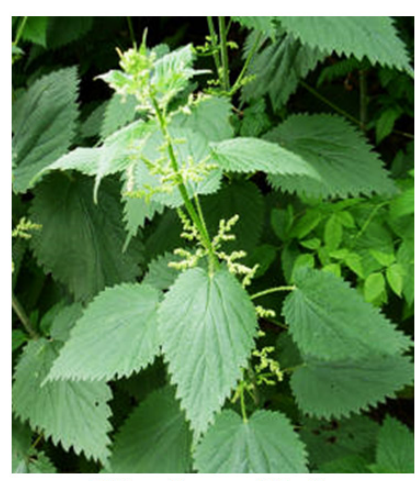

Urtica dioica
Figure 1. Morphology of aerial parts of L.Album and U. dioica.

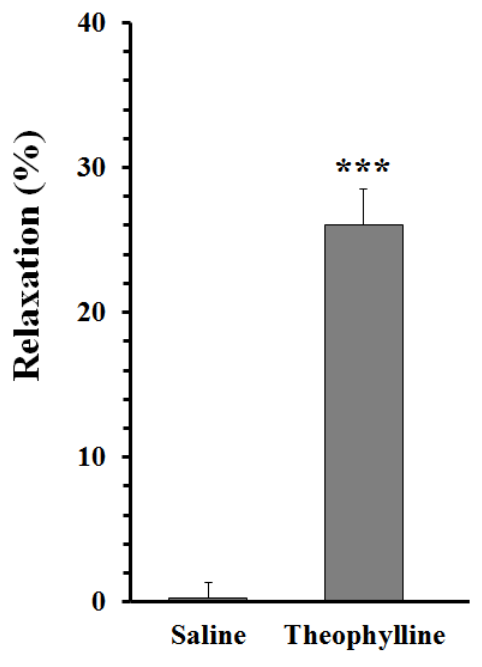

Figure 2. Effect of theophylline on rat tracheal contraction. The contraction was induced by $60 \mathrm{mM} \mathrm{KCl}$. When the contraction reached a plateau (100\%), saline (vehicle) or theophylline $(20 \mathrm{mM})$, were added $(0.1 \mathrm{ml})$ to organ bath and the changes in contractile force were recorded. Data are mean \pm SEM $(n=6) .{ }^{* * *} p<0.001$ as compared with saline.

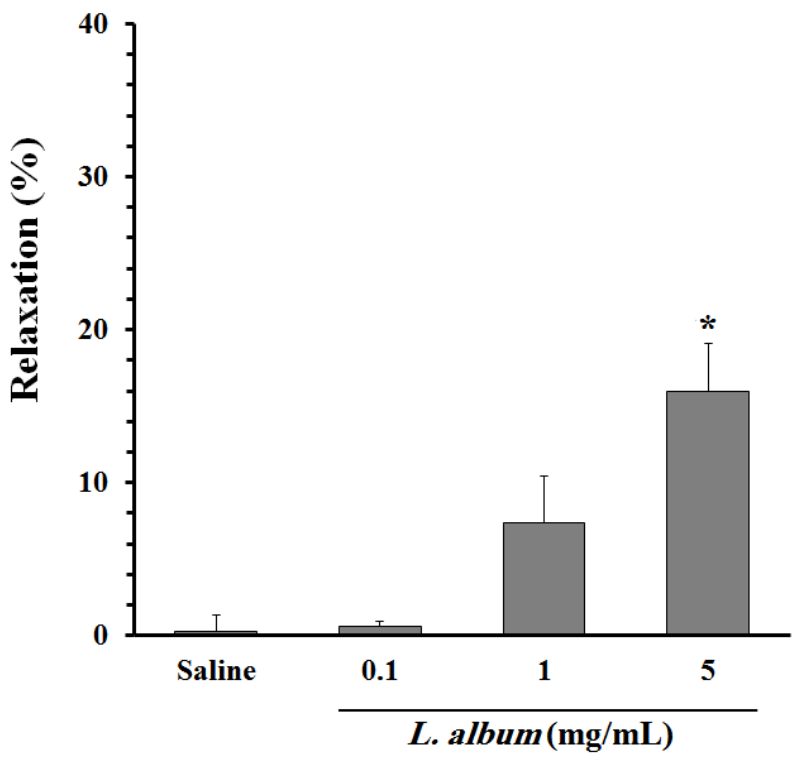

Figure 3. Effect of hydroalcoholic extract of L. album on rat tracheal contraction. The contraction was induced by $60 \mathrm{mM} \mathrm{KCl}$. When the contraction reached a plateau (100\%), saline (vehicle), or the extract was added $(0.1 \mathrm{ml})$ to organ bath and the changes in contractile force were recorded. Data are mean $\pm \operatorname{SEM}(n=6) .{ }^{*} \mathrm{p}<$ 0.05 as compared with saline. 


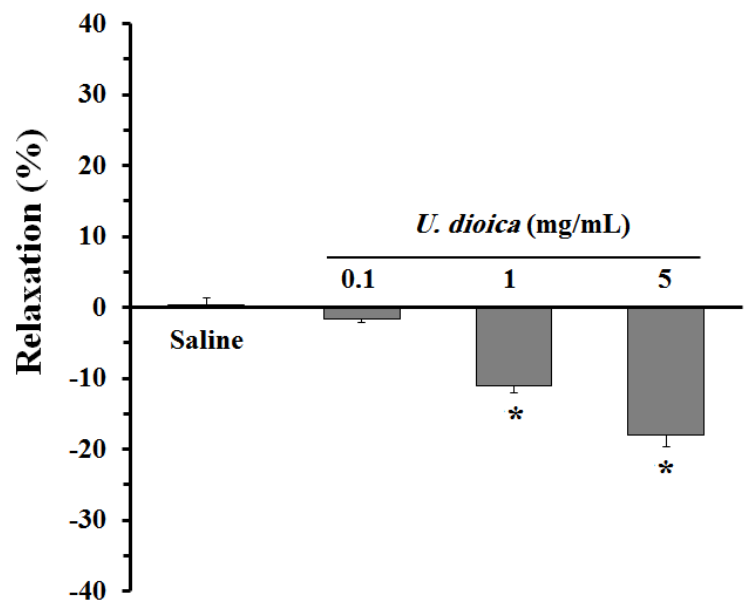

Figure 4. Effect of hydroalcoholic extract of U. Dioica on rat tracheal contraction. The contraction was induced by $60 \mathrm{mM} \mathrm{KCl}$. When the contraction reached a plateau (100\%), saline (vehicle), or the extract was added $(0.1 \mathrm{ml})$ to organ bath and the changes in contractile force were recorded. Data are mean $\pm \operatorname{SEM}(n=6)$. ${ }^{*} \mathrm{p}<$ 0.05 compared with saline. 


\section{References}

1. http://www.who.int/respiratory/asthma/en/

2. Banerji D, Fogel R, Beeh KM. Dual bronchodilation for the treatment of chronic obstructive pulmonary disease: a review of the latest clinical data. Clin Invest 2014;4:511-533.

3. Doeing DC, Solway J. Airway smooth muscle in the pathophysiology and treatment of asthma. J Appl Physiol. 2013;114:834-843.

4. Bozzola E, Bozzola M, Barberi S, Cutrera R, Villani A. Safety and potential side effects of $邓 2$-agonists: a still debated question. Int J Pediatr Child Health. 2013;1:4-10.

5. Haney S, Hancox RJ. 2006. Recovery from bronchoconstriction and bronchodilator tolerance. Clin Rev Allergy Immunol.31:181-196.

6. Djelili H, Arrar L, Naline E, Devillier P. Relaxant effects of quercetin and rutin on human isolated bronchus. Chin Med. 2012;3:94-100.

7. Shakeri F, Boskabady MH. A review of the relaxant effect of various medicinal plants on tracheal smooth muscle, their possible mechanism(s) and potency. J Ethnopharmacol. 2015;175:528-548.

8. Jafarzade P, Mohseni Mehran S M, Moladoust H, Norasfard M R, Ghorbani A, Abedinzade M. Effect of Hydroalcoholic Extract of Anethum graveolens L. Seed on Tracheal Smooth Muscle Contractions in Male Rats. J Mazandaran Univ Med Sci. 2018; 28 (160) :146-150.

9. Pereira OR, Domingues MRM, Silva AMS, Cardoso SM. Phenolic constituents of Lamium album: focus on isoscutellarein derivatives. Food Res Int. 2012;48:330-335.

10. Bubueanu C, Gheorghe C, Pirvu L, Bubueanu G. Antioxidant activity of butanolic

extracts of Romanian native species - Lamium album and Lamium purpureum. Rom

Biotechnolog Let. 2013;18:8855-8862.

11. Chipeva VA, Petrova DC, Geneva ME, Dimitrova MA, Moncheva PA, Kapchina-Toteva

VM. Antimicrobial activity of extracts from in vivo and in vitro propagated Lamium

album L. plants. Afr J Tradit Complement Altern Med. 2013;10:559-562.

12. Mohseni Mehran SM, M Abedinzade $M^{*}$,Norasfard MR , Khanaki K. Lamium album or Urtica dioica? Which is more effective in decreasing serum glucose, lipid and hepatic enzymes in streptozotocin induced diabetic rats: a comparative study.

African Journal of Traditional, Complementary and Alternative medicines (AJTCAM)

, 2015, 12 (5): 84-88.

13. Topouzova-Hristova T, Moskova-Doumanova V, Keremidarska M, Doumanov J, Miteva G, Petkova B, Kapchina-Toteva V. Anticancer effect of plant extracts from Lamium album L. by induction of cell death in vitro. Sci Technolog. 2012;2:55-59.

14. Gruenwald J, Brendler T, Jaenicke C. Physician's Desk Reference (PDR) for Herbal Medicines. Medical Economics Company Inc., Montvale; 2000.

15. Ghasemi S, Moradzadeh M, Mousavi SH, Sadeghnia HR. Cytotoxic effects of Urtica dioica radix on human colon (HT29) and gastric (MKN45) cancer cells mediated through oxidative and apoptotic mechanisms Cell Mol Biol (Noisy-le-grand). 2016;62:90-96.

16. Golalipour MJ, Khori V. The protective activity of Urtica dioica leaves on blood glucose concentration and beta-cells in streptozotocin-diabetic rats. Pak J Biol Sci. 2007;10:1200-1204.

17. Gülçin I, Küfrevioglu OI, Oktay M, Büyükokuroglu ME. Antioxidant, antimicrobial, antiulcer and analgesic activities of nettle (Urtica dioica L.). J Ethnopharmacol. 2004;90:205-215.

18. Qayyum R, Qamar HM, Khan S, Salma U, Khan T, Shah AJ. Mechanisms underlying the antihypertensive properties of Urtica dioica. J Transl Med. 2016;14:254.

19. Ghorbani A, Hadjzadeh MR, Rajaei Z, Zendehbad SB. Effects of fenugreek seeds on adipogenesis and lipolysis in normal and diabetic rat. Pak J Biol Sci. 2014;17:523528.

20. Hosseini A, Mollazadeh H, Amiri MS, Sadeghnia HR, Ghorbani A. Effects of a standardized extract of Rheum turkestanicum Janischew root on diabetic changes in the kidney, liver and heart of streptozotocin-induced diabetic rats. Biomed Pharmacother. 2017;86:605-611.

21. Gharib Naseri MK, Heidari A. The bronchodilatory activity of Vitis vinifera leaf hydroalcoholic extract in rat. Iran Biomed J. 2006;10:79-83.

22. Otles S, Yalcin B. Phenolic compounds analysis of root, stalk, and leaves of nettle. ScientificWorldJournal. 2012;564367.

23. Aviello G, Scalisi C, Fileccia R, Capasso R, Romano B, Izzo AA, Borrelli F. Inhibitory effect of caffeic acid phenethyl ester, a plant-derived polyphenolic compound, on rat intestinal contractility. Eur J Pharmacol. 2010;640:163-167.

24. Dizaye KF, Alberzingi BO, Sulaiman SR. Renal and vascular studies of aqueous extract of Urtica dioica in rats and rabbits. Iraq J Vet Sci. 2013;27:25-31.

25. Collier HOJ, Chesher GB. Identification of 5-hydroxytryptamine in the sting of the nettle (Urtica dioica). Brit J Pharmacol. 1956;11:186-189. 